Article

\title{
A Cause and Effect Model for Digital Sustainable Supply Chain Competitiveness under Uncertainties: Enhancing Digital Platform
}

\author{
Ming-Lang Tseng ${ }^{1,2,3}$, Tat-Dat Bui ${ }^{1} \mathbb{D}$, Ming K. Lim ${ }^{4,5, *}$ and Stephen Lewi ${ }^{6}$ \\ 1 Institute of Innovation and Circular Economy, Asia University, Taichung 413, Taiwan; \\ tsengminglang@asia.edu.tw (M.-L.T.); buitatdat@asia.edu.tw (T.-D.B.) \\ 2 Department of Medical Research, China Medical University Hospital, China Medical University, \\ Taichung 404, Taiwan \\ 3 Faculty of Economic and Management, University Kebangsaan Malaysia, Bangi 43600, Malaysia \\ 4 College of Mechanical and Vehicle Engineering, Chongqing University, Chongqing 400044, China \\ 5 Centre for Business in Society, Coventry University, Coventry CV1 5FB, UK \\ 6 Department of Business Administration, Asia University, Taichung 413, Taiwan; stephenlewi97@gmail.com \\ * Correspondence: ming.lim@coventry.ac.uk
}

\section{check for}

updates

Citation: Tseng, M.-L.; Bui, T.-D.; Lim, M.K.; Lewi, S. A Cause and Effect Model for Digital Sustainable Supply Chain Competitiveness under Uncertainties: Enhancing Digital Platform. Sustainability 2021, 13, 10150. https://doi.org/10.3390/ su131810150

Academic Editors: Benny Tjahjono, Jennifer Ferreira, David Bek and Natalia Yakovleva

Received: 22 July 2021

Accepted: 30 August 2021

Published: 10 September 2021

Publisher's Note: MDPI stays neutral with regard to jurisdictional claims in published maps and institutional affiliations.

Copyright: (c) 2021 by the authors. Licensee MDPI, Basel, Switzerland. This article is an open access article distributed under the terms and conditions of the Creative Commons Attribution (CC BY) license (https:// creativecommons.org/licenses/by/ $4.0 /)$.

\begin{abstract}
This study provides insights into digitalization in sustainable supply chain management by establishing a structural set of attributes with causal interrelationships among them, as well as by reporting empirical findings on successful criteria for footwear supply chain practices in Indonesia. Sustainable supply chain management and digitalization are mutual benefits. However, there are unclear cause and effect interrelationships. This study aims to critically pinpoint digitalization to approach sustainability and is designed to help firms achieve supply chain competitiveness. The fuzzy Delphi method and fuzzy decision-making trial and evaluation laboratory are utilized, due to the fuzziness associated with human decision making and the complexity and uncertainty in the supply chain. Five aspects and seventeen criteria are validated. The findings indicate that four aspects, including digital platform effectiveness, digital communication belonging to the supply chain digitalization perspective, labour conditions, and manufacturing processes, are important to sustainable supply chain management. The top causal criteria, including logistics integration, logistics optimization, delivery speed, proactive action, and real-time inventory, are considered to assist firms in implementing better practices.
\end{abstract}

Keywords: sustainable supply chain management; digitalization; digital platform effectiveness; digital communication; fuzzy DEMATEL

\section{Introduction}

Sustainable supply chain management (SSCM) has become a vital tool with which firms can control costs and maximize economic performance. It also faces heavy pressure with respect to adopting practices to achieve socioenvironmental sustainability [1,2]. Alkhuzaim et al. [3] highlighted that SSCM strives to sustainably accomplish the flow of resources and information for product/service releases by means of technical procedures that connect the upstream and downstream parts of the supply chain (SC). Tsai et al. [4] argued that SSCM requires complete integration to manage the acquisition, manufacturing, and distribution of products or services while effectively and efficiently improving the long-term connections between firms and their SC partners. However, current SC management practices, which merely pursue economic benefits, are not a sound alternative for firms from a long-term sustainability viewpoint [5]. Industries worldwide are wrestling to integrate SSCM into their business systems [2]. This includes the footwear industry, which is no longer self-sufficient in a competitive market, thereby forcing firms to adopt SSCM to continue strengthening their profitability and move towards sustainability [6]. 
A couple of years ago, developing nations and consumers started to increase their awareness of sustainable practices and demand that firms adopt SC processes to improve their socioenvironmental sustainability [2]. In Indonesia, the footwear industry contributes to the nation's economy. The country is one of the major footwear manufacturers worldwide and ranks fourth after China, India, and Vietnam [7]. The industry had a total value (domestic and export) of USD 7.97 billion in 2017, with an export growth rate of $8.97 \%$ in $2020[8,9]$. However, a plethora of sustainability issues, such as environmental damage and social conditions, are common in the footwear sector and could lead to unattractiveness to buyers [10]. Therefore, it is important for the footwear industry in Indonesia to incorporate SSCM practices to achieve operational excellence while solving social and environmental problems.

While designing SSCM, the sustainability perspectives of society, the environment, and the economy (triple bottom line-TBL) should be integrated to achieve continued sustainability performance [3]. Tseng et al. [11] indicated that balancing TBL and integrating it into the SC network has received significant attention among academics and practitioners. Ahmed and Sarkar [12] stated that firms directly consider TBL as the combination of different aspects of sustainable development. However, SSCM is fuzzy due to the limited compromise on social and environmental SC performance, as well as tangible economic outcomes. There are still gaps in achieving sustainable SC development. Digital technologies, such as personal computers, mobile devices, self-driving vehicles and drones, and wearable devices such as smartphones and smartwatches, have changed the ways in which people approach and exchange information. These emergent innovative technologies touch every business, including SC and logistics services, and support effective collaboration and communication among SC partners. Büyüközkan and Göçer [6] argued that current emerging digital technology has a huge impact across SC and industry, which makes it dynamic and volatile, thus forcing firms to keep strengthening their profitability and sustainability in a competitive market. Annosi et al. [13] claimed that digital technologies improve collaboration, encourage the growth of new business models, and improve firms' profitability. Beaulieu and Bentahar [14] proposed that the implementation of digital technology helps to achieve flexibility and efficiency in SSCM by synchronizing the flow of information in SC processes. Barrett and Scott [15] argued that the digital, technical, coefficient-given industry SSCM is embodied in a circular economy that includes fresh resources, energy, equipment, services, properties, and transportation, all of which are required for production lines. Firms are also encouraged to integrate their SC process into digital technology applications [16,17]. Nevertheless, uneven digitalization among partners can cause potential disruptions within SC, and how to address SSCM under the great effect of digitalization remains unclear. This study intends to establish the digitalization perspective as critical to the SSCM approach and to help firms achieve SC competitive advantages.

Due to the complexity and uncertainty of SSCM, this study used the fuzzy Delphi method (FDM) and fuzzy decision-making trial and evaluation laboratory (FDEMATEL) approaches [4]. The FDM is used to eliminate less significant criteria and validate aspects identified in the literature by computing experts' linguistic reference perception levels, which have been proven to yield practical improvement under uncertainties [18,19]. Moreover, FDEMATEL is used to explore causal interrelationships among attributes [4]. Hence, this study's objectives are as follows:

- To determine a structural set of attributes in SSCM;

- To identify the causal interrelationship among attributes;

- To determine important attributes for SSCM in footwear industry practices in Indonesia.

This study contributes to the literature on digitalization in SSCM by (1) providing insight by determining and identifying a structure attribute set; (2) specifying causal interrelationships among attributes; and (3) offering empirical findings and successful criteria for footwear SSCM improvement. 
The study is organized into six sections. Section 1 introduces the concept of SSCM and digitalization. Section 2 presents the literature on SSCM and digitalization, proposes the methodology of the study, and discusses the proposed measures. Section 3 more clearly explains the methodology used. Section 4 will present the findings. Section 5 provides theoretical and managerial implications. Finally, the conclusion is addressed in Section 6.

\section{Literature Review}

This section discusses SSCM, digitalization in SC, the proposed methodology, and the measurement attribute set.

\subsection{Sustainable Supply Chain Management}

SSCM has grown exponentially and plays a vital role in SC management by addressing competitive markets and various environmental and social issues [1,3]. SSCM is defined as the strategies, transparent incorporation, and organizational goal achievement in the interorganizational occupational process coordinated to improve the long-term economic, social, and environmental performance of specific firms and their SCs [5]. SSCM contributes to linking business development and sustainability issues. Hong et al. [1] claimed that SSCM combined elements of business sustainability development and characteristics of SC management. Tseng et al. [20] and Khan et al. [2] argued that SSCM activities are triggered by external pressures, the government, customers, and NGOs and pursue good economic performance by ensuring the effectiveness and efficiency of product consumption and waste generation in operational functions. In sum, SSCM supervises SC activities, operations, information, and resources with the aims of refining economic benefits and social welfare and of reducing harmful environmental effects simultaneously for sustainable development.

However, increasing environmental issues and numerous pressures to balance SSCM and stakeholder benefits in conventional activities still exist, although the literature suggests that firms need to adopt sustainable dimensions in SC management. Tsai et al. [4] argued that firms need to focus on the integration of social development, environmental issues, and economic consequences in the SSCM process. Hu et al. [21] debated that by adopting SSCM, firms can also improve profitability, operational effectiveness, and competitive advantage by reducing waste and achieving socioenvironmental performance. Genovese et al. [22] claimed that the practices of SSCM result in the principles of a circular economy by disclosing a compromising drive to promote the SC loop cycle border. However, the changeover to sustainability is a challenging process, as a wide range of limitations, including cultural, political, and economic structures, as well as human and technological confines, arise [22]. Hence, SSCM still has many gaps to be addressed to achieve long-term sustainability performance [3].

\subsection{Digitalization in Supply Chain}

Digitalization in SSCM is defined as connecting activities involved in the SC process between suppliers and consumers by means of novel technologies [6]. Digitalization in SC (DSC) and its impacts have been discussed in prior studies. However, it is considered an emerging term [14,23]. Bhargava et al. [23] specified that the DSC was systematically composed of hardware, software, and global communication networks supporting organizational interaction and orchestrating SC stakeholder activity. However, as an emergent term, digitalization is still in the early conceptualization stage, which is under similar theoretical underpinnings [14]. Queiroz et al. [24] proposed that digitalization is based on the growth of data and communication technologies. Nasiri et al. [25] argued that digitalization is a transformation of business aspects (process, organizational, and culture) as required by the market. This perspective connects the existing processes at the societal, organizational, and individual levels, thus fostering the transformation of traditional SC into an interconnected system that runs flawlessly [26]. 
DSC has the potential to transform the SC to make it more valuable, accessible, and affordable. DSC provides information sharing, collaboration, and communication through digital platforms, resulting in advanced reliability, agility, and effectiveness [6]. Firms are starting to consider digitality because of the huge number of benefits digitality can bring for firms by utilizing it in SC. Nasiri et al. [25] proposed that digitality changes the ways companies and individuals communicate and interact with their surroundings in an extreme manner. Fettermann et al. [27] claimed that the interconnectedness within SC needs collaboration among diverse technologies, such as sensors, cloud processing, and cyber-physical practices, to encourage management transformation towards Industry 4.0. Annosi et al. [13] argued that high-performance DSC integration allows an increase in financial performance and is beneficial for sustainability. Kianpour et al. [28] proposed integrating digital technology with real-time information on processing times and due date rescheduling decisions to adapt to dynamic situations. Nevertheless, challenges exist in building DSCs due to the accuracy of the information, but the required data need to be collected from various sources. Therefore, to achieve sustainable development, a wellestablished SC should be extended to the application of digital technology and integrated into a firm's SC $[15,17,25]$. Hence, there is a need for firms to reimagine their SC process as a DSC network to reach development goals.

\subsection{Proposed Method}

Prior studies have used many methods to analyse SSCM. For instance, Munny et al. [10] formulated and applied the best-worst method to assess social sustainability enablers in SC. Filho et al. [29] used a qualitative method on multiple cases to characterize cleaner production opportunities and challenges. Moktadir et al. [30] used a Pareto analysis combined with the best-worst method to categorize and rank the risk factors related to SSCM. However, there are few studies that include the fuzziness in human decision making under the complexity and uncertainty of SSCM. Therefore, a more suitable method is needed.

This study uses the fuzzy Delphi method (FDM) and fuzzy DEMATEL (FDEMATEL) method. First, FDM is used to eliminate unnecessary attributes from experts' linguistics [19]. This method allows experts to barter judgements with each other and supports uncertainty and complexity reductions through these expert judgements; then, survey analysis quality is guaranteed [31,32]. The FDEMATEL method is then used to identify human perceptions of linguistic preferences and interrelationships among attributes [33]. Additionally, by addressing their interrelationships, FDEMATEL is appropriate to specify the imperative attributes [4].

\subsection{Proposed Measure}

The SSCM literature has addressed various attributes. These attributes have a significant role that helps decision makers focus their effort on achieving more efficient performance. This study identifies 35 criteria and 8 aspects from 4 perspectives, namely, the economic dimension, the social dimension, the environmental dimension, and SC digitalization, for measuring processes (See Table 1).

The economic dimension is still the priority, and firms may initially emphasize an SC process that minimizes waste and yields economic gains [3,35]. Economic benefits (A1) are a basic condition that firms must pursue to achieve economic performance and development [11]. SC competitiveness (A2) is an economic concern [35]. Previous studies have proposed investment recovery $(\mathrm{C} 1)$, which means recoupling the surplus assets value and reducing the waste of initial capital, which results in efficiency. The production stage (C2) refers to ensuring process feasibility based on the efficiency of manufacturing processes and material costs. Operation practices (C3) are related to economics of scale in transportation, both outbound and inbound, scientific inventory control, or just-in-time and lean production. Strategic supplier collaboration (C4) refers to collaboration between firms and their suppliers in the SC that applies innovative technologies [19]. Product quality (C5) refers to creating a high-value product. Logistic integration (C6) is the coordination of the 
material flow from suppliers to customers. Logistic optimization (C7) optimizes the logistic process in SC, including the pace, path, load, and character of transportation. Sourcing flexibility (C8) refers to the ability to respond to market uncertainties and changes [2].

Table 1. Proposed measurement.

\begin{tabular}{|c|c|c|c|c|}
\hline & Perspective & Aspects & Criteria & Literature Review \\
\hline \multirow{2}{*}{ P1 } & \multirow{2}{*}{ Economy } & Economy benefit & $\begin{array}{l}\text { Investment recovery } \\
\text { Production stage } \\
\text { Operations practices } \\
\text { Strategic supplier collaboration }\end{array}$ & \multirow{2}{*}[11,18,34]{} \\
\hline & & SC competitiveness & $\begin{array}{l}\text { Product quality } \\
\text { Logistics integration } \\
\text { Logistics optimization } \\
\text { Sourcing flexibility }\end{array}$ & \\
\hline \multirow{2}{*}{ P2 } & \multirow{2}{*}{ Social } & Society benefit & $\begin{array}{c}\text { Social collaboration } \\
\text { Corporate practice transparency } \\
\text { Social responsibility } \\
\text { Top management commitment }\end{array}$ & \multirow{2}{*}[10,34-36]{} \\
\hline & & Labour condition & $\begin{array}{l}\text { Working conditions } \\
\text { Worker safety } \\
\text { Labour rights } \\
\text { Child labour or forced labour }\end{array}$ & \\
\hline \multirow{2}{*}{ P3 } & \multirow{2}{*}{ Environment } & Material sourcing & $\begin{array}{c}\text { Green purchasing } \\
\text { Eco collaboration } \\
\text { Supplier green management } \\
\text { Recycling (or reverse logistics) }\end{array}$ & \multirow{2}{*}{ [37-39] } \\
\hline & & Manufacturing processes & $\begin{array}{l}\text { Cleaner production } \\
\text { Waste minimization and recovery } \\
\text { Green packaging } \\
\text { Eco product design }\end{array}$ & \\
\hline \multirow[t]{2}{*}{$\mathrm{P} 4$} & \multirow[t]{2}{*}{$\begin{array}{l}\text { Supply chain } \\
\text { digitalization }\end{array}$} & $\begin{array}{l}\text { Digital platform } \\
\text { effectiveness }\end{array}$ & $\begin{array}{c}\text { Delivery speed } \\
\text { Adaption flexibility } \\
\text { Autonomous decision making } \\
\text { Process scalability } \\
\text { Innovative approaches } \\
\text { Proactive action } \\
\text { Eco-friendly }\end{array}$ & \multirow[t]{2}{*}{ [6] } \\
\hline & & Digital communication & $\begin{array}{c}\text { Global connectivity } \\
\text { Real-time inventory } \\
\text { Information transparency } \\
\text { Relationship performance }\end{array}$ & \\
\hline
\end{tabular}

Although social sustainability is deemed an intricate aspect, it is relatively neglected and infrequently accounted for in SSCM models $[10,36]$. There are two aspects with eight criteria that are proposed in this study. Social benefit (A3) represents social activities that seek to benefit employees, customers, and local communities. Labour condition (A4) is related to issues such as labour rights, child labour, and exploitative labour practices [35]. Social collaboration (C9) is collaboration that involves SC stakeholders to improve social outcomes. Corporate practice transparency (C10) concerns internal and external stakeholders that are becoming demanding for visible and transparent corporate practices. Social responsibility (C11) refers to the social awareness and activities in the SC process to support humanity and do no harm to communities. Top management commitment (C12) ensures the initiation of action and the dedication of resources to implement a social sustainability SC [10]. Working condition (C13) ensures a higher living level and provides clear terms of employment, including salaries and benefits, full and stable employment, vacation, disciplinary regulations, and parenthood and dismissal fortifications. Worker safety (C14) complies with governments' regulations regarding working safety. Labour rights (C15) refer to respect for the rights of labourers to form unions and groups [37]. Child labour or forced labour (C16) is any kind of forced labour, including underage labour. 
Environmental sustainability encompasses the management of resources, so waste from processes does not harm the natural environment or humankind [38]. This perspective is apprehensive with finding and unravelling difficulties associated with pollution and damage related to the flow of resources and production stability [25]. In this context, an approach that emphasizes a circular economy as a green and closed system is suggested in alignment with SSCM strategies, as resources are depleted and waste reduction becomes important once environmental sustainability constraints are imposed [16,23]. This study proposes two aspects from the environmental sustainability perspective. Material sourcing (A5) consists of supplier selection and collaboration. Manufacturing processes (A6) is a concept of administrating consumption and production activities. Green purchasing (C17) relates to environmentally preferable purchasing items, such as non-hazardous items, reusability, and recyclability. Eco collaboration (C18) means collaboration between SC stakeholders to reduce waste, lessen the carbon footprint, and conserve resources [38]. Supplier green management (C19) is a collaboration between firms and their suppliers to be environmentally responsible, have a green certification, and evaluate suppliers' environmental performance [39]. Recycling or reverse logistics (C20) is related to the efficient processing, from the end user back to the point of origin, of material and information that can be disposed of or have its value regenerated. Cleaner production (C21) efficiently reduces hazardous material and toxic emissions from the process. Waste minimization and recovery (C22) means waste management that minimizes waste, prevents waste from being generated, and attempts to make waste recoverable. Green packaging (C23) includes adopting renewable materials and minimizing the usage of resources. Eco-design (C24) represents product or service design that embeds green value [39].

In SC digitalization, Büyüközkan and Göçer [6] proposed the features of DSC. For example, digital platform effectiveness (A7) is related to the ability to enhance reliability, agility, and effectiveness in the SSCM process by using digital platforms. Digital communication (A8) refers to SC interactions and stakeholder activities. Delivery speed (C25) means the ability to quickly transfer extra material within a specified amount of time. Adaption flexibility (C26) refers to the ability to adapt to changing circumstances and respond to problems in SC. Autonomous decision making (C27) is related to the ability of digital technology that provides smart products that can self-learn and make decisions autonomously based on defined algorithms. Process scalability (C28) means facilitating process duplication and growth by utilizing digital technology. The innovative approach (C29) is related to the DSC distinction as a key characteristic of continuously being open for changes. Proactive action (C30) means that DSCs gain abilities to mitigate potential disruptions. Eco-friendliness (C31) relates to digital technology that can extend the traditional SC process to make it cleaner with respect to the environment. Global connectivity (C32) enables firms to efficiently supply products locally across the world. Real-time inventory (C33) means that DSC helps firms efficiently meet demand by ensuring that the supply is not disproportionately in surplus or shortage. Information transparency (C34) ensures that the orderly flow within $\mathrm{SC}$ is visible to stakeholders and is not disrupted. Relationship performance (C35) refers to collaborations built for conducting business, both internally and externally, between companies and their stakeholders.

\section{Methodology}

\subsection{Industrial Background}

In Indonesia, the footwear industry is one of the prioritized industries because this industry is labour intensive and export oriented. As one of the largest footwear producers in the world, Indonesia also contributed as much as $4.6 \%$ to the world footwear supply in 2018 [7]. However, this industry is still using a basic SC process that results in low-valueadded products. Several efforts have been made by the Ministry of Industry of Indonesia [7] and the Indonesian Footwear Association [8] to support the adoption of digitalization in the footwear industry. Furthermore, this industry is progressing to such innovative paradigms 
as fast fashion, street fashion, and quick fashion, which have characteristics such as short market cycles.

However, this industry also contributes significantly to social and environmental issues, such as poor working conditions, insufficient wages, an absence of fire safety, long working hours, child labour, gender inequality, poverty and health conditions, poor contaminated waste disposal, effluents in the soil and water, and toxin emissions that can be harmful to humans and the environment [10]. Therefore, to achieve sustainability and increase both the export value and the domestic sector value, there is a need to restructure the SC process. Digitalization can serve as a significant attribute in contributing to this transition stage. This study is performed to facilitate the footwear industry in Indonesia by providing a better understanding of the causality of SSCM and digitalization in the industry in terms of information-driven strategies, real-time data, and quick responses to current market information and public feedback. This study collected the data from 30 respondents with an average of 10 years of experience in the field, including 26 expert professional managers and 4 faculty member experts who have experience studying the supply chain management field (in Appendix A Table A1).

\subsection{Fuzzy Delphi Method}

The FDM initially originated as the combination of fuzzy set theory and the Delphi method to address expert reference limitations and advance questionnaire quality [40,41].

For instance, suppose that there are $n$ experts simultaneously assessing the level of importance of attribute $m$ as $k=\left(x_{a b} ; y_{a b} ; z_{a b}\right), a=1,2,3, \ldots, n ; b=1,2,3, \ldots, m$, where $k_{b}=\left(x_{b} ; y_{b} ; z_{b}\right)$ is the weight of $b$ with $x_{b}=\min \left(x_{a b}\right), k_{b}=\left(\prod_{1}^{n} y_{a b}\right)^{1 / n}$, and $z_{b}=\max \left(z_{a b}\right)$. The experts' linguistic references are interpreted into triangular fuzzy numbers (TFNs) as shown in Table 2.

Table 2. Transformation table of linguistic terms for FDM.

\begin{tabular}{cc}
\hline Linguistic Terms (Performance/Importance) & Corresponding Triangular Fuzzy Numbers (TFNs) \\
\hline Extreme & $(0.75,1.0,1.0)$ \\
Demonstrated & $(0.5,0.75,1.0)$ \\
Strong & $(0.25,0.5,0.75)$ \\
Moderate & $(0,0.25,0.5)$ \\
Equal & $(0,0,0.25)$ \\
\hline
\end{tabular}

Using a $g$ cut, the convex mixture values are generated as:

$$
o_{b}=x_{b}-g\left(z_{b}-y_{b}\right), s_{b}=x_{b}-g\left(y_{b}-g x_{b}\right),
$$

where $b=1,2,3, \ldots, m$ and $g=[0,1]$ indicates whether experts' perceptions are positive or negative. A value of $g=0.5$ denotes the general perception condition.

The precise $L_{b}$ value is interpreted using fuzzy values as:

$$
L_{b}=\int\left(o_{b}, s_{b}\right)=t\left[o_{b}+(1-\sigma) s_{b}\right],
$$

where $t=0.5$ represents the equilibrium of the expert's optimistic assessment.

Afterwards, the threshold is attained as $D=\left(\sum_{b=1}^{m} L_{b}\right) / m$ to validate attributes from the initial set.

If $L_{b} \geq D$, attribute $b$ is valid, and if $L_{b}<D$, attribute $b$ is removed.

\subsection{Fuzzy Decision-Making Trial and Evaluation Laboratory}

The FDEMATEL translates qualitative information into TFNs and converts them into script values via a defuzzification process. An attribute set $A=\left\{a_{1}, a_{2}, \cdots, a_{n}\right\}$ is offered, using confidential pairwise assessments to represent scientific interactions. Implicitly, a 
group of $e$ experts take part in the assessment, and, as shown in Table 3, the TFNs use linguistic scales from $\mathrm{VH}$ (very high influence) to VL (very low influence) to obtain the crisp values.

Table 3. TFNs linguistic scale.

\begin{tabular}{ccc}
\hline Scale & Linguistic Variable & Corresponding Triangular Fuzzy Number (TFNs) \\
\hline VH & Very high influence & $(0.7,0.9,1.0)$ \\
H & High influence & $(0.5,0.7,0.9)$ \\
M & Moderate influence & $(0.3,0.5,0.7)$ \\
L & Low influence & $(0.1,0.3,0.5)$ \\
VL & Very low influence & $(0.0,0.1,0.3)$ \\
\hline
\end{tabular}

The $\widetilde{k}_{i j}^{e}$ term represents the influential fuzzy weight of the $i$ th attribute to the $j$ th attribute evaluated by expert $e$ by using the fuzzy membership functions, $\widetilde{k}_{i j}^{e}=\left(\widetilde{k}_{1 i j}^{e}, \widetilde{k}_{2 i j}^{e}, \widetilde{k}_{3 i j}^{e}\right)$. The TFNs are curtailed using:

$$
A=\left(a \widetilde{k}_{1 i j}^{e}, a \widetilde{k}_{2 i j}^{e}, a \widetilde{k}_{3 i j}^{e}\right)=\left[\frac{\left(k_{1 i j}^{e}-\min k_{1 i j}^{e}\right)}{\max k_{3 i j}^{e}-\min k}, \frac{\left(k_{2 i j}^{e}-\min k_{2 i j}^{e}\right)}{\max k_{3 i j}^{e}-\min k}, \frac{\left(k_{3 i j}^{e}-\min k_{3 i j}^{e}\right)}{\max k_{3 i j}^{e}-\min k}\right] .
$$

The normalized left $(n l)$ and right $(n r)$ values are calculated using:

$$
\left(n l_{i j}^{n}, n r_{i j}^{n}\right)=\left[\frac{\left(q k_{2 i j}^{e}\right.}{\left(1+q k_{2 i j}^{e}-q k_{1 i j}^{e}\right)}, \frac{q k_{3 i j}^{e}}{\left(1+q k_{3 i j}^{e}-q k_{2 i j}^{e}\right)}\right] .
$$

The normalized crisp values $(n c)$ are determined using:

$$
n v_{i j}^{e}=\frac{\left[n l_{i j}^{e}\left(1-n l_{i j}^{e}\right)+\left(n r_{i j}^{e}\right)^{2}\right]}{\left(1-n l_{i j}^{e}+n r_{i j}^{e}\right)}
$$

The total crisp values are gathered from the $e$ respondents' individual responses using:

$$
\widetilde{k}_{i j}^{e}=\frac{\left(n v_{i j}^{1}+n v_{i j}^{2}+n v_{i j}^{3}+\cdots+n v_{i j}^{3}\right)}{k} .
$$

The $n \times n$ initial direct relation matrix $(I R)$ is assimilated as $I R=\left[\widetilde{k}_{i j}^{e}\right]_{n \times n}$. The normalized direct relation matrix $(N R)$ is generated as:

$$
N R=\frac{1}{\max _{1 \leq i \leq k} \sum_{j=1}^{e} \widetilde{k}_{i j}^{e}} \otimes I R
$$

The interrelationship matrix $(I M)$ is then obtained using:

$$
I M=N R(I-N R)^{-1},
$$

where $\left[I M_{i j}\right]_{n \times n} i, j=1,2, \cdots n$.

The driving level $(D I)$ and dependence level $(D P)$ are assimilated following the sum value of the matrix (IM) row and column using:

$$
D I=\left[\sum_{i-1}^{n} I M_{i j}\right]_{n \times n}=\left[I M_{i}\right]_{n \times 1}
$$




$$
D P=\left[\sum_{j-1}^{n} I M_{i j}\right]_{n \times n}=\left[I M_{j}\right]_{1 \times n}
$$

Accordingly, the attributes are situated in the cause-and-effect diagram derived from $[(D I-D P),(D I+D P)]$ as vertical and horizontal vectors. The cause-and-effect groups are classified depending on whether their $(D I-D P)$ values are positive or negative. If $(D I-D P)<0$, the attributes are assigned to the cause group; if not, they are assigned to the effect group. The $(D I+D P)$ signifies the attributes' importance. The higher the $(D I+D P)$ value, the more important the attribute is among the set.

\subsection{Analysis Steps}

The analysis is performed in two stages (shown in Figure 1):

1. FDM is used to eliminate the less significant attributes and validate aspects and criteria identified in the literature.

2. FDEMATEL is used to explore causal interrelationships among attributes and identify the important attributes with respect to implications.

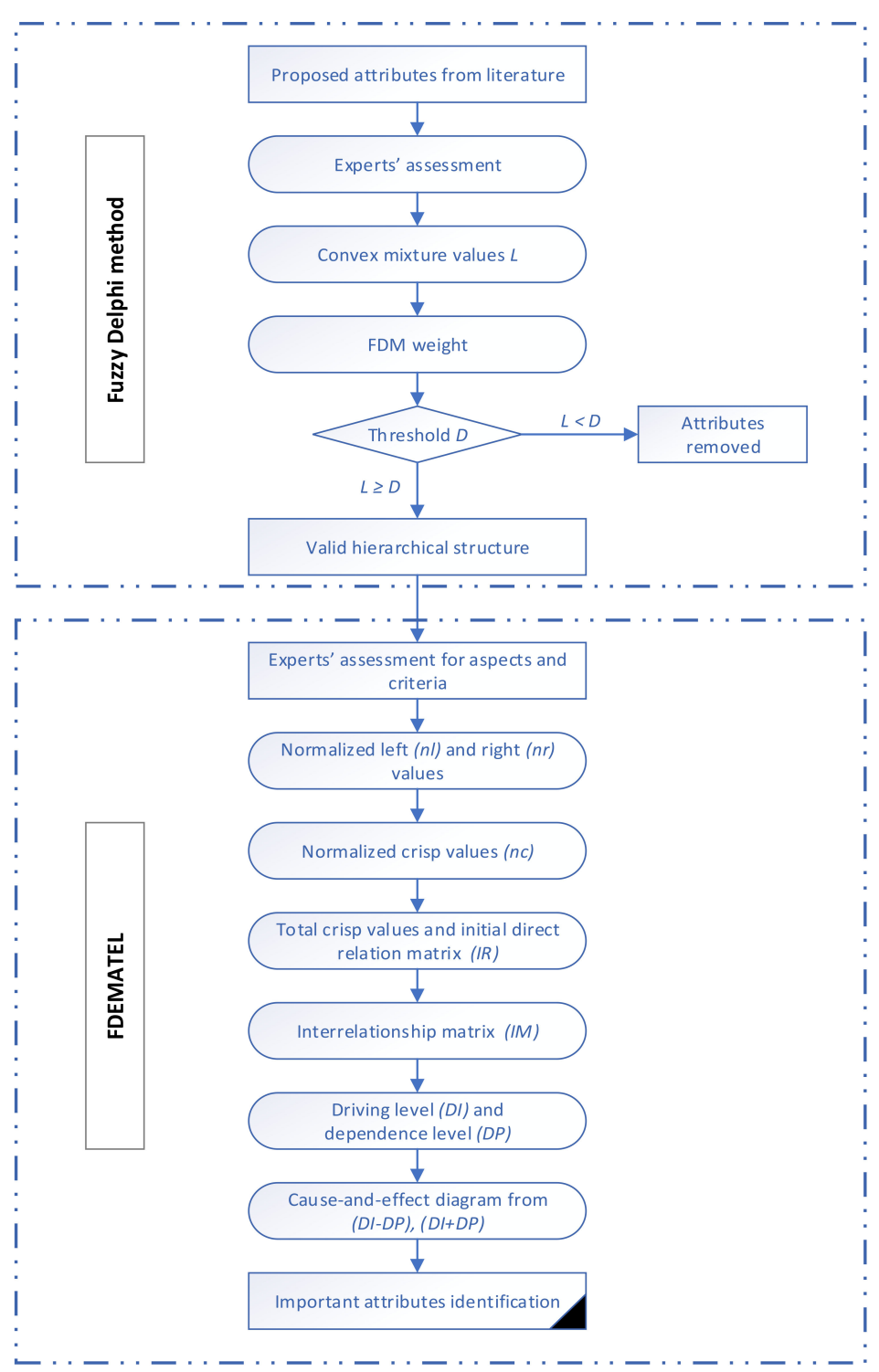

Figure 1. Analysis steps. 


\section{Result}

The results from the FDM and FDEMATEL analyses are presented in this section.

\subsection{Fuzzy Delphi Method}

An initial set of 8 aspects and 35 criteria is proposed based on four perspectives: economy (P1), social (P2), environmental (P3), and SC digitalization (P4), as stated in Table 4. Then, experts evaluated the aspects and criteria based on their expertise, judgement, and linguistic terms and converted them into TFNs. The FDM analysis of aspect and criteria is shown in Appendix A Tables A2 and A3. The valid aspects and criteria are determined with thresholds of $D=0.641$ and 0.628 , respectively. Five out of eight aspects and 17 out of 35 criteria are acceptable indicators that are used in the next phase of the FDEMATEL analysis.

Table 4. FDM results.

\begin{tabular}{|c|c|c|c|c|c|}
\hline & Perspective & & Aspects & & Criteria \\
\hline \multirow{5}{*}{ P1 } & \multirow{5}{*}{ Economy } & \multirow{5}{*}{ A1 } & \multirow{5}{*}{ Supply chain competitiveness } & C1 & Product quality \\
\hline & & & & $\mathrm{C} 2$ & Logistics integration \\
\hline & & & & $\mathrm{C} 3$ & Logistics optimization \\
\hline & & & & $\mathrm{C} 4$ & Sourcing flexibility \\
\hline & & & & C5 & Working conditions \\
\hline \multirow[t]{2}{*}{ P2 } & \multirow{2}{*}{ Social } & \multirow{2}{*}{ A2 } & \multirow{2}{*}{ Labour condition } & C6 & Worker safety \\
\hline & & & & C7 & Labour rights \\
\hline \multirow[t]{4}{*}{ P3 } & \multirow[t]{4}{*}{ Environment } & \multirow[t]{3}{*}{ A3 } & \multirow[t]{3}{*}{ Manufacturing processes } & $\mathrm{C} 8$ & Cleaner production \\
\hline & & & & C9 & Delivery speed \\
\hline & & & & C10 & Adaption flexibility \\
\hline & & A4 & Digital platform effectiveness & C11 & Process scalability \\
\hline \multirow{6}{*}{$\mathrm{P} 4$} & \multirow{6}{*}{$\begin{array}{l}\text { Supply chain } \\
\text { digitalization }\end{array}$} & & & $\mathrm{C} 12$ & Innovative approaches \\
\hline & & \multirow{5}{*}{ A5 } & \multirow{5}{*}{ Digital communication } & $\mathrm{C} 13$ & Proactive action \\
\hline & & & & C14 & Global connectivity \\
\hline & & & & C15 & Real-time inventory \\
\hline & & & & C16 & Information transparency \\
\hline & & & & C17 & Relationship performance \\
\hline
\end{tabular}

\subsection{Fuzzy Decision-Making Trial and Evaluation Laboratory}

The attribute set from the FDM is evaluated by experts to determine the aspects' average crisp values for calculation in the initial direction matrix (in Table 5). Additionally, an interrelationship matrix is generated to acquire the causal interrelationships of the attributes (in Table 6). The interrelationship matrix includes five aspects: SC competitiveness (A1), labour condition (A2), manufacturing processes (A3), digital platform effectiveness (A4), and digital communication (A5). Then, the cause-and-effect diagram is presented in Figure 2. The cause-and-effect aspects that are shown as (A2), (A3), (A4), and (A5) are in the cause group, whereas (A1) is in the effect group. Specifically, (A4) and (A5) are the main aspects influencing SSCM, as they have strong and medium influences on each other, respectively. Digital platform effectiveness and digital communication also have a strong influence on SC competitiveness and a moderate influence on labour conditions and manufacturing processes. Furthermore, labour conditions and manufacturing processes have moderate effects on SC competitiveness.

Table 5. Synthetic script values for aspects.

\begin{tabular}{cccccc}
\hline & A1 & A2 & A3 & A4 & A5 \\
\hline A1 & 3.578 & 2.299 & 2.314 & 2.415 & 2.466 \\
A2 & 2.711 & 3.615 & 2.576 & 2.624 & 2.690 \\
A3 & 2.763 & 2.547 & 3.646 & 2.639 & 2.676 \\
A4 & 3.003 & 2.754 & 2.831 & 3.962 & 2.956 \\
A5 & 3.035 & 2.784 & 2.820 & 2.941 & 4.027 \\
\hline
\end{tabular}


Table 6. Total interrelationship matrix and cause-and-effect values among aspects.

\begin{tabular}{cccccccccc}
\hline & A1 & A2 & A3 & A4 & A5 & DI & DP & $($ DI+DP $)$ & $($ DI - DP $)$ \\
\hline A1 & 2.578 & 2.299 & 2.314 & 2.415 & 2.466 & 12.072 & 14.091 & 26.163 & -2.018 \\
A2 & 2.711 & 2.615 & 2.576 & 2.624 & 2.690 & 13.216 & 12.998 & 26.215 & 0.218 \\
A3 & 2.763 & 2.547 & 2.646 & 2.639 & 2.676 & 13.272 & 13.186 & 26.458 & 0.085 \\
A4 & 3.003 & 2.754 & 2.831 & 2.962 & 2.956 & 14.506 & 13.582 & 28.089 & 0.924 \\
A5 & 3.035 & 2.784 & 2.820 & 2.941 & 3.027 & 14.607 & 13.815 & 28.422 & 0.791 \\
\hline
\end{tabular}

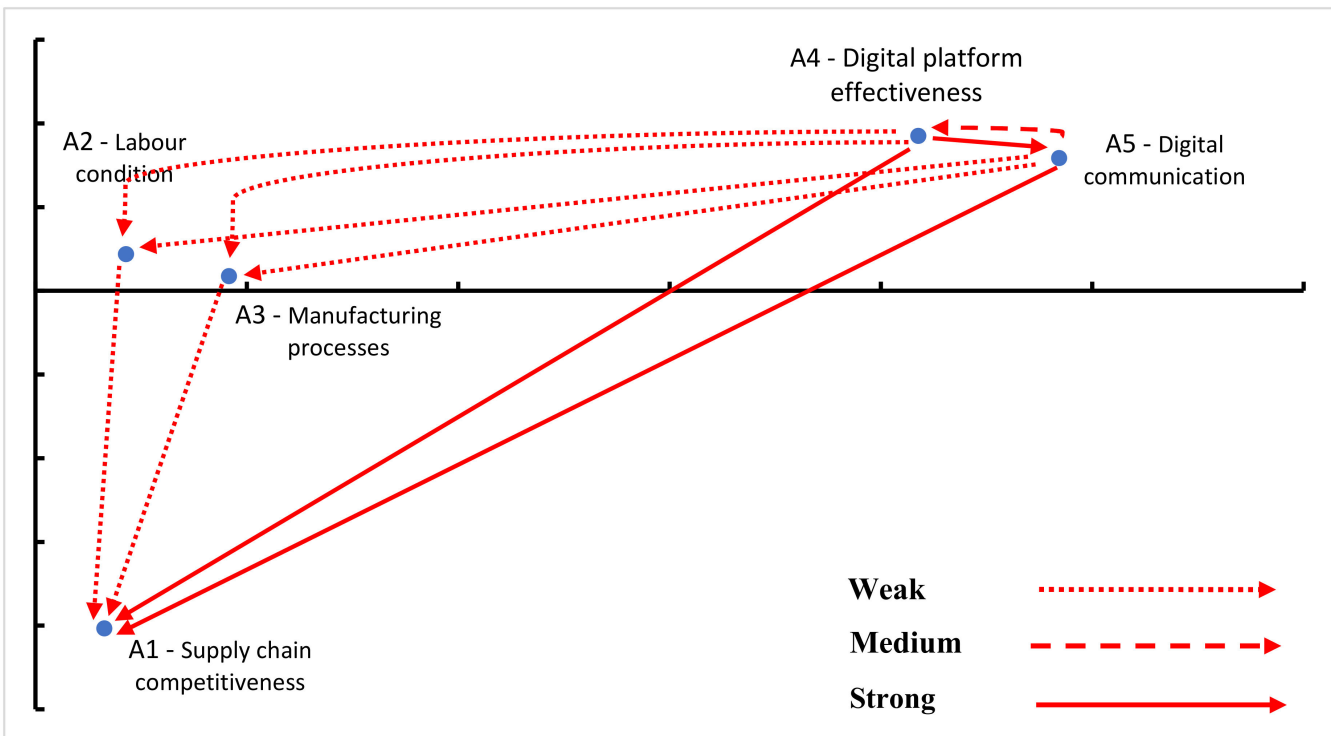

Figure 2. Causal interrelationship diagram for aspects.

Additionally, the interrelationship matrix for the criteria was generated (shown in Table 7), and the causal interrelationships were obtained (shown in Table 8). The results reveal that $\mathrm{C} 2, \mathrm{C} 3, \mathrm{C} 6, \mathrm{C} 9, \mathrm{C} 12, \mathrm{C} 13, \mathrm{C} 14, \mathrm{C} 15, \mathrm{C} 16$, and $\mathrm{C} 17$ are the causal criteria and that the effect group consists of C1, C4, C5, C7, C8, C10, and C11 (in Figure 3). Among these, the more important criteria in the cause group are logistics integration (C2), logistics optimization (C3), delivery speed (C9), proactive action (C13), and real-time inventory (C15).

Table 7. Total interrelationship matrix among criteria.

\begin{tabular}{|c|c|c|c|c|c|c|c|c|c|c|c|c|c|c|c|c|c|}
\hline & $\mathrm{C} 1$ & $\mathrm{C} 2$ & $\mathrm{C} 3$ & C4 & C5 & C6 & C7 & $\mathrm{C} 8$ & C9 & C10 & C11 & C12 & $\mathrm{C} 13$ & C14 & C15 & C16 & C17 \\
\hline $\mathrm{C} 1$ & 0.747 & 0.746 & 0.734 & 0.722 & 0.639 & 0.599 & 0.550 & 0.655 & 0.717 & 0.690 & 0.723 & 0.693 & 0.662 & 0.689 & 0.711 & 0.696 & 0.654 \\
\hline $\mathrm{C} 2$ & 0.764 & 0.792 & 0.770 & 0.765 & 0.670 & 0.634 & 0.572 & 0.671 & 0.757 & 0.719 & 0.751 & 0.716 & 0.703 & 0.715 & 0.741 & 0.733 & 0.698 \\
\hline $\mathrm{C} 3$ & 0.756 & 0.771 & 0.777 & 0.758 & 0.657 & 0.614 & 0.567 & 0.667 & 0.755 & 0.712 & 0.744 & 0.705 & 0.696 & 0.711 & 0.734 & 0.726 & 0.692 \\
\hline $\mathrm{C} 4$ & 0.694 & 0.718 & 0.698 & 0.726 & 0.620 & 0.575 & 0.533 & 0.612 & 0.704 & 0.672 & 0.690 & 0.661 & 0.652 & 0.665 & 0.689 & 0.680 & 0.655 \\
\hline $\mathrm{C} 5$ & 0.643 & 0.652 & 0.648 & 0.636 & 0.595 & 0.546 & 0.495 & 0.568 & 0.638 & 0.608 & 0.625 & 0.589 & 0.595 & 0.585 & 0.602 & 0.600 & 0.592 \\
\hline C6 & 0.640 & 0.648 & 0.648 & 0.641 & 0.573 & 0.571 & 0.517 & 0.574 & 0.629 & 0.597 & 0.621 & 0.593 & 0.589 & 0.594 & 0.610 & 0.606 & 0.585 \\
\hline $\mathrm{C} 7$ & 0.537 & 0.548 & 0.545 & 0.545 & 0.483 & 0.485 & 0.466 & 0.486 & 0.535 & 0.519 & 0.530 & 0.509 & 0.502 & 0.510 & 0.516 & 0.522 & 0.496 \\
\hline $\mathrm{C} 8$ & 0.594 & 0.585 & 0.581 & 0.569 & 0.508 & 0.494 & 0.455 & 0.554 & 0.583 & 0.561 & 0.580 & 0.555 & 0.539 & 0.541 & 0.554 & 0.544 & 0.526 \\
\hline C9 & 0.750 & 0.763 & 0.759 & 0.752 & 0.659 & 0.630 & 0.583 & 0.661 & 0.760 & 0.698 & 0.731 & 0.703 & 0.674 & 0.691 & 0.718 & 0.720 & 0.682 \\
\hline C10 & 0.651 & 0.659 & 0.650 & 0.648 & 0.575 & 0.545 & 0.497 & 0.576 & 0.631 & 0.643 & 0.641 & 0.602 & 0.604 & 0.611 & 0.633 & 0.601 & 0.587 \\
\hline C11 & 0.704 & 0.717 & 0.709 & 0.697 & 0.615 & 0.592 & 0.532 & 0.614 & 0.696 & 0.654 & 0.712 & 0.665 & 0.654 & 0.663 & 0.683 & 0.671 & 0.642 \\
\hline C12 & 0.708 & 0.720 & 0.712 & 0.705 & 0.621 & 0.573 & 0.530 & 0.632 & 0.706 & 0.665 & 0.688 & 0.684 & 0.650 & 0.658 & 0.679 & 0.660 & 0.634 \\
\hline C13 & 0.737 & 0.761 & 0.755 & 0.748 & 0.648 & 0.619 & 0.577 & 0.664 & 0.743 & 0.713 & 0.729 & 0.695 & 0.710 & 0.694 & 0.715 & 0.712 & 0.675 \\
\hline C14 & 0.712 & 0.732 & 0.724 & 0.715 & 0.619 & 0.578 & 0.539 & 0.617 & 0.713 & 0.677 & 0.702 & 0.676 & 0.672 & 0.695 & 0.689 & 0.682 & 0.668 \\
\hline C15 & 0.733 & 0.751 & 0.746 & 0.742 & 0.629 & 0.599 & 0.554 & 0.630 & 0.727 & 0.694 & 0.717 & 0.685 & 0.686 & 0.694 & 0.731 & 0.705 & 0.680 \\
\hline C16 & 0.720 & 0.739 & 0.731 & 0.722 & 0.620 & 0.592 & 0.549 & 0.624 & 0.716 & 0.687 & 0.712 & 0.660 & 0.664 & 0.680 & 0.704 & 0.711 & 0.668 \\
\hline C17 & 0.702 & 0.716 & 0.715 & 0.707 & 0.610 & 0.578 & 0.536 & 0.617 & 0.704 & 0.671 & 0.693 & 0.661 & 0.652 & 0.663 & 0.689 & 0.682 & 0.673 \\
\hline
\end{tabular}


Table 8. Cause-and-effect values for criteria.

\begin{tabular}{ccccc}
\hline & $\boldsymbol{D I}$ & $\boldsymbol{D P}$ & $(\boldsymbol{D I}+\boldsymbol{D P})$ & $(\boldsymbol{D I}-\boldsymbol{D P})$ \\
\hline C1 & 11.626 & 11.794 & 23.420 & $(0.167)$ \\
C2 & 12.171 & 12.016 & 24.187 & 0.155 \\
C3 & 12.042 & 11.901 & 23.943 & 0.140 \\
C4 & 11.243 & 11.797 & 23.041 & $(0.554)$ \\
C5 & 10.217 & 10.340 & 20.557 & $(0.124)$ \\
C6 & 10.236 & 9.824 & 20.060 & 0.411 \\
C7 & 8.732 & 9.050 & 17.782 & $(0.319)$ \\
C8 & 9.323 & 10.423 & 19.746 & $(1.100)$ \\
C9 & 11.935 & 11.715 & 23.650 & 0.219 \\
C10 & 10.355 & 11.181 & 21.536 & $(0.826)$ \\
C11 & 11.220 & 11.588 & 22.808 & $(0.367)$ \\
C12 & 11.225 & 11.052 & 22.277 & 0.174 \\
C13 & 11.895 & 10.903 & 22.798 & 0.992 \\
C14 & 11.413 & 11.059 & 22.472 & 0.353 \\
C15 & 11.701 & 11.400 & 23.101 & 0.302 \\
C16 & 11.498 & 11.250 & 22.748 & 0.249 \\
C17 & 11.268 & 10.806 & 22.074 & 0.462 \\
\hline
\end{tabular}

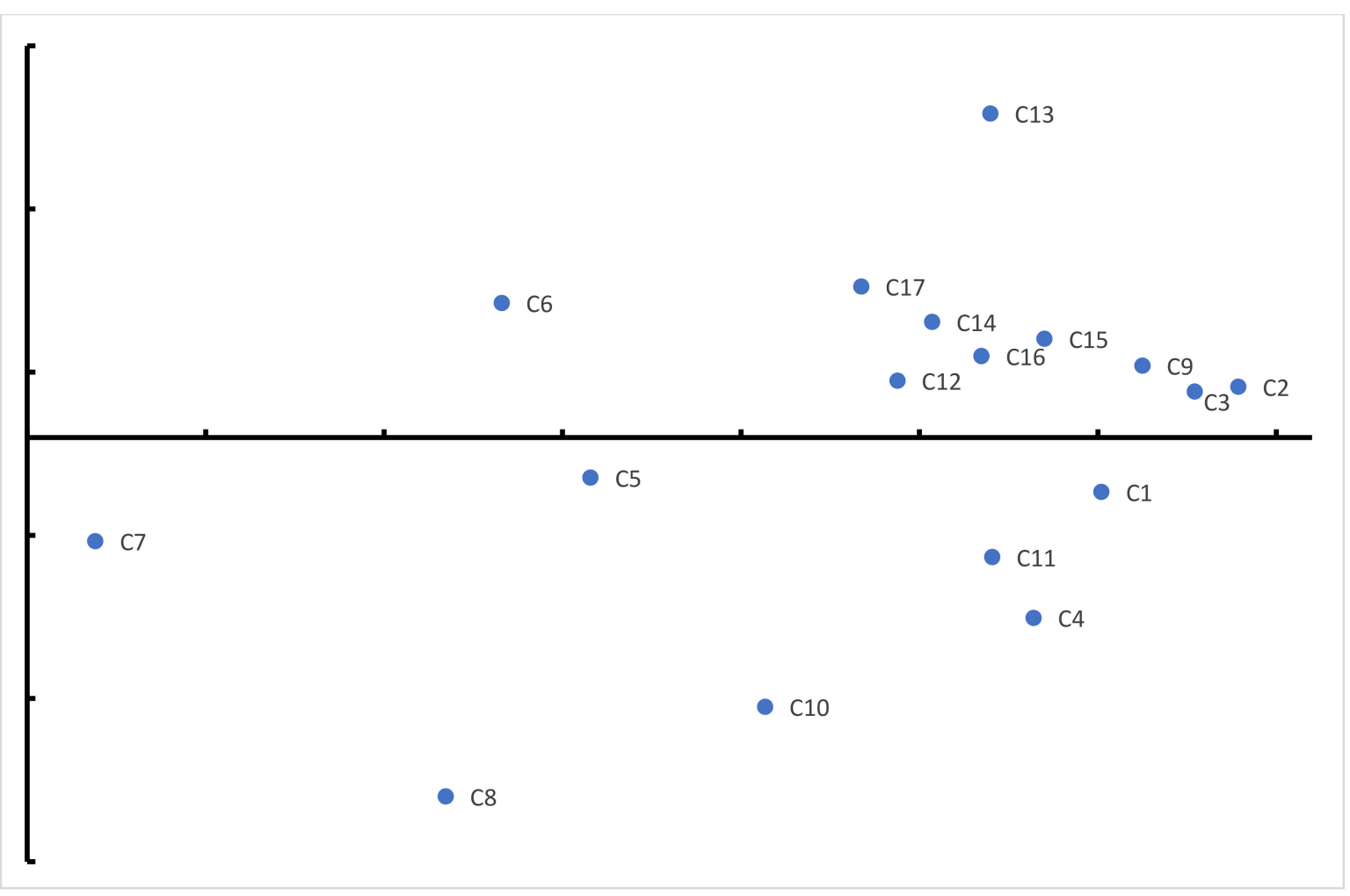

Figure 3. Cause-and-effect diagram for criteria.

\section{Implications}

This section presents the theoretical and managerial implications of SSCM.

\subsection{Theoretical Implications}

This study provides theoretical insights based on causal SSCM aspects. The results reveal that there are four causal aspects that need to be focused on, including labour conditions and manufacturing processes. From the SC digitalization perspective, digital communication and digital platform effectiveness must be specially prioritized to improve SSCM. 
This study finds that digital communication is demonstrated to be the main causal aspect. This aspect is critical to SSCM, as it can support the interactions of SC stakeholders. The results of this study confirm that digital communication is important because it affects the SSCM model and that digital communication is required in better synchronizing interaction in the SC system [6]. Improving digital communication can enhance sustainability as it drives SC competitiveness in the economic dimension and enhances social and environmental performance. This aspect is the advantage that a firm can obtain from an SSCM process, as SC is currently no longer used only to move materials; it also integrates and coordinates complex activities. Therefore, digital communication can ensure that the SSCM process and the flow of material and information can efficiently be integrated while also giving a firm the ability to quickly respond to any changes in the market. Moreover, this aspect allows visibility and collaboration across the entire SSCM process, thus promoting interaction between SSCM stakeholders and resulting in a more sustainable and more valuable process.

Digital platform effectiveness refers to the benefit of using DSC to make widespread information available across digital platforms, which results in increases to the reliability, agility, and effectiveness of the SSCM. The interrelationship between digital platform effectiveness and digital communication in SSCM and SC competitiveness is highlighted. The strong influence of digital platform effectiveness on digital communication proves that digitalization results in superior collaboration and communication [6]. Therefore, this aspect is argued to help ensure that the interaction between stakeholders is flexible and efficient because it synchronizes all the information in the whole SSCM process so that information can be processed into valuable insights. As one of the critical aspects, digital platform effectiveness offers enhancement of financial performance while also contributing to the social and environmental performance of the SSCM process [13]. Flexibility and efficiency, which are gained from digital platform effectiveness, result in less cost, less waste, and faster responses to the market, thus providing competitiveness and better socioenvironmental performance.

Although labour conditions in the social dimension have weak effects within SSCM systems, they are still found in the causal group in this study. This result confirms that the social dimension is necessary with respect to the sustainability elements of the SSCM process [1,3]. In SSCM, the social sustainability perspective is employed by ensuring good labour conditions, as labour is a valuable asset to the firm and is one of the key attributes of long-term sustainability. Failure to establish good labour conditions affects the relations between firms and their stakeholders, since many stakeholders place pressure on firms to ensure sustainability [10]. Therefore, it is particularly vital for SC systems to achieve more durable working practices for workers in maintaining SSCM. Firms are obliged to take this aspect into account because it assists in achieving sustainable development.

Similarly, manufacturing processes in the environmental dimension are also found to be causal aspects, which demonstrates the importance of this dimension in the SSCM process [1,3]. This aspect is an approach to manufacturing processes that is safer for the environment and meets the stakeholder demand for sustainable goods by consistently reducing the amount of toxic raw material used and evaluating the process to eliminate waste before it exits production. As firms are becoming aware and guaranteeing that negligible harm is caused to the ecosystem, knowledge of the impact of manufacturing processes on the environment is needed both for survival in the modern market and to satisfy stakeholders [36]. Therefore, the need to prioritize a manufacturing process with a clean and greener production line is important for firms that aim to incorporate sustainable development into their SC processes. The circular economic implications that align with SSCM should be noted as the principle of supernumerary raw material usage and cleaner and greener manufacturing production systems [16,22,42]. The circular supply chain design comprises a cohesive supply chain model in which a product reverts from the end-user and a recovery process, such as repair, reuse, recycling, or remanufacture, is suggested. 


\subsection{Managerial Implications}

This subsection confers managerial implications to the Indonesian footwear SC practice. Logistics integration, logistics optimization, delivery speed, proactive action, and real-time inventory are practical attributes regarding SSCM.

Logistics integration extends to everything related to the operational and logistics endeavours that align the material flow, from the original point to end-consumption throughout the value stream. It also ensures that the materials arrive at the right time and in the right quantity. As a process, logistic integration enables firms and their stakeholders to proceed in a unified manner. The criteria include collaboration and relationships with both internal and external SC stakeholders to ensure that both information and materials flow smoothly between stakeholders. This allows footwear firms to know about changes in the SC process, reduce the bullwhip effect, and be able to efficiently adjust the needed resources, such as transportation, warehousing, and labour capacities, in advance. Therefore, firms can run their SCs more smoothly and sustainably with lower cost, lead time, and risk, thus improving SSCM and competitiveness.

Logistics optimization relates to the needs of an effective and efficient SC process to achieve better sustainability. This criterion helps firms optimize production costs and times and improves quality. However, the common nature of footwear logistics activities is environmentally unfriendly, as the industry produces waste and emissions that are harmful to human health. Therefore, firms are required to optimize their logistic systems to make them either easier or cheaper, which presents a great opportunity to reduce costs and enhance competitive advantages, as stakeholders are starting to increase awareness of sustainable practices and demand the adoption of this criterion in their SCs for better socioenvironmental sustainability. This enhances firm profitability. However, given the complexity involved, logistics optimization is a never-stop system. Current best practices may change over time due to fluctuations within the SC process as well as of a firm's specific situation and stakeholders. Hence, commitment and constant monitoring are needed to maintain efficiency, effectiveness, and sustainability.

Delivery speed means the ability to move more material in a shorter time. Faster delivery and fulfilment are becoming trends among not only consumers who desire to obtain the product but also footwear firms and their SC partners, who demand faster fulfilment, smaller order sizes with higher frequency, greater customization, and shorter product innovation cycles. Moreover, with the help of DSC, delivery speed is a useful instrument with which to address industry-specific challenges, especially dynamic and fast-moving information on consumer demands and trends. This criterion offers a faster pace of business and makes delivery in every stage of SSCM more efficient. By making the process more efficient, delivery speed will bring cost, time, and resource savings, thus ensuring sustainability. Therefore, firms need to adjust the process to speed the process up. However, speed alone is not enough, as SSCM also needs to be reliable and responsive to potential disruptions.

Proactive action means preventing potential disruption in the SC process. This criterion is important for firms, as firms should prepare for disruption, as disruption is inevitable. There is no way to insulate SSCM from disruptive events better than to be prepared before they happen, and currently, being truly proactive is possible. The rise of digital technology and its integration into SSCM implementation gives firms new capabilities to mitigate potential disruptions and ensure sustainability. Digital enablers in a connected SC system give firms insight and the ability to analyse the process as a whole, as well as detect and immediately anticipate potential disruptions before they affect the process, preventing firms from being reactive. Moreover, the SC can be overwhelmed by the day-to-day process, and when disruption occurs, the earlier information is provided to the stakeholder, the better firms can work to find more resilient and sustainable decisions. In other words, it gives firms and stakeholders more time to respond to the potential disruption. Hence, a more accurate solution is obtained with less waste and damage in the entire SC, as well as an easier recovery. 
Real-time inventory helps firms efficiently meet demand by ensuring that the on-hand stock is neither in surplus nor in shortage. In the Indonesian market, customer behaviour is changing rapidly such that firms always need to be ready to respond to it. In contrast to periodic inventory updates, real-time inventory utilizes digital technology to record every transaction, both inbound and outbound. As soon as material is sourced, the item can appear in stock. Likewise, the product stock should decrease as soon as it is purchased. Digital technology makes inventory management in SSCM more efficient. Moreover, in an SC in a short market cycle, visibility is essential to ensure that firms' inventories are resilient and can quickly respond to the market. A lack of comprehensive visibility could result in the lack of SC planning, processing, and integration, introducing inefficiency to the whole process. Therefore, this aspect can help firms continuously monitor stock levels in real time. Thus, trends and future demand for services can be recognized in advance, and firms can react quickly with SC decisions.

\section{Conclusions}

SSCM and digitalization have been popular topics over the last few years; however, limited studies have aligned these two concepts or studied the SC practices of the footwear industry. First, to address this gap, this study applied FDM to identify valid attributes and eliminate unnecessary attributes. From experts' judgement, five aspects, namely, SC competitiveness, labour conditions, manufacturing processes, digital platform effectiveness, and digital communication, are proposed with 17 criteria based on the SSCM theme. Second, FDEMATEL was adopted to explore the cause-and-effect grouping of these attributes to signify the structural interrelationships and critical effects among them in achieving SSCM.

The findings indicate that four aspects are considered causal attributes: digital platform effectiveness, digital communication, labour conditions, and manufacturing processes. From the SC digitalization perspective, digital platform effectiveness and digital communication are the main causal SSCM aspects which have the potential to enhance SSCM performance. Digital communication and digital platform effectiveness are found to be the basis of enhanced SC competitiveness, labour conditions, and manufacturing processes. Digital communication is crucial in better synchronizing the interaction of the SSCM process. Digital platform effectiveness ensures the availability of information across digital platforms and makes the SSCM process reliable, agile, and effective. Furthermore, this study reveals that the 17 criteria are also divided into a cause-and-effect assembly. The top causal criteria are acknowledged as logistics integration, logistics optimization, delivery speed, proactive action, and real-time inventory, which can assist firms in better integrating and coordinating the whole process of SSCM in the footwear industry in Indonesia.

The contributions of this study provide insight through identifying and determining a structural set of attributes and the interrelationships among those present in SSCM. Digitalization is found to be the most significant attribute in enhancing SSCM, as this attribute provides a new perspective in handling SSCM and helps managers improve SSCM performance. In other words, digitalization synchronizes everything related to the traditional SSCM process to ensure that both information and materials flow smoothly and that firms can be flexible to respond to the market, while also supporting the improvement of sustainability in the SC management process by preventing and reducing waste and potential disruption. Digitalization has a powerful effect on TBL, SC competitiveness, labour conditions, and manufacturing processes.

However, several limitations still exist. First, the current attributes were collected from the literature; thus, the attributes might not be fully comprehensive. Future studies may integrate more attributes in future evaluations. Second, this study used the FDM and FDEMATEL methods to assess the evaluation of the aspects and criteria. These methods are useful for identifying attributes and interrelationships in uncertain and complex environments. Nevertheless, the background relies on the committee's experience and knowledge, which possibly introduces subjective intentions that could impact the results of 
this study. Extending the number of committee members could be beneficial to overcome this limitation. Third, this study concentrated only on the Indonesian footwear industry, which limits its scientific generalizability. Future studies are recommended to accumulate data from other countries and industries to increase the contribution and augment SSCM.

Author Contributions: Conceptualization, M.-L.T. and M.K.L.; methodology, M.-L.T. and T.-D.B.; software, T.-D.B.; validation, M.-L.T., M.K.L. and S.L.; formal analysis, M.-L.T., T.-D.B. and M.K.L.; investigation, T.-D.B. and S.L.; resources, M.K.L.; data curation, T.-D.B.; writing-original draft preparation, M.-L.T., T.-D.B. and M.K.L.; writing—review and editing, M.-L.T., T.-D.B., M.K.L. and S.L.; visualization, S.L.; supervision, M.-L.T. and M.K.L.; project administration, M.-L.T. All authors have read and agreed to the published version of the manuscript.

Funding: This research received no external funding.

Institutional Review Board Statement: Not applicable.

Informed Consent Statement: Not applicable.

Data Availability Statement: Not applicable.

Conflicts of Interest: The authors declare no conflict of interest.

\section{Appendix A}

Table A1. Respondents' demographic.

\begin{tabular}{|c|c|c|c|c|}
\hline Experts & Position & Education Level & $\begin{array}{c}\text { Years of } \\
\text { Experience }\end{array}$ & $\begin{array}{l}\text { Organization Type } \\
\text { (Academia/Practice) }\end{array}$ \\
\hline 1 & Lecturer & Ph.D. & 7 & Faculty member \\
\hline 2 & Lecturer & Master & 5 & Faculty member \\
\hline 3 & Lecturer & Master & 6 & Faculty member \\
\hline 4 & Lecturer & Master & 8 & Faculty member \\
\hline 5 & Managing director & Master & 15 & Practitioner \\
\hline 6 & Managing director & Master & 10 & Practitioner \\
\hline 7 & Managing director & Master & 8 & Practitioner \\
\hline 8 & $\begin{array}{l}\text { Director of } \\
\text { international } \\
\text { business } \\
\text { Development }\end{array}$ & Ph.D. & 12 & Practitioner \\
\hline 9 & Director & Ph.D. & 10 & Practitioner \\
\hline 10 & Director & Master & 20 & Practitioner \\
\hline 11 & Director & Master & 18 & Practitioner \\
\hline 12 & Director & Master & 9 & Practitioner \\
\hline 13 & Director & Bachelor & 8 & Practitioner \\
\hline 14 & Director & Master & 6 & Practitioner \\
\hline 15 & Director & Master & 8 & Practitioner \\
\hline 16 & Vice president & Master & 26 & Practitioner \\
\hline 17 & General manager & Master & 12 & Practitioner \\
\hline 18 & Division head & Master & 7 & Practitioner \\
\hline 19 & Department head & Master & 9 & Practitioner \\
\hline 20 & $\begin{array}{l}\text { International } \\
\text { business manager }\end{array}$ & Master & 12 & Practitioner \\
\hline 21 & Manager & Master & 10 & Practitioner \\
\hline 22 & Manager & Master & 8 & Practitioner \\
\hline 23 & Manager & Master & 6 & Practitioner \\
\hline 24 & Manager & Bachelor & 20 & Practitioner \\
\hline 25 & Manager & Bachelor & 5 & Practitioner \\
\hline 26 & Supervisor & Bachelor & 8 & Practitioner \\
\hline 27 & Supervisor & Bachelor & 8 & Practitioner \\
\hline 28 & Supervisor & Bachelor & 8 & Practitioner \\
\hline 29 & Supervisor & Bachelor & 6 & Practitioner \\
\hline 30 & Supervisor & Bachelor & 5 & Practitioner \\
\hline
\end{tabular}


Table A2. FDM results for aspects.

\begin{tabular}{ccccc}
\hline Initial Aspects & $\boldsymbol{o}_{\boldsymbol{b}}$ & $\boldsymbol{s}_{\boldsymbol{b}}$ & $\boldsymbol{L}_{\boldsymbol{b}}$ & Decision \\
\hline Economy benefit & 0.000 & 0.500 & 0.333 & Unaccepted \\
SC competitiveness & -0.043 & 0.918 & 0.695 & Accepted \\
Society benefit & -0.385 & 0.885 & 0.590 & Unaccepted \\
Labor condition & -0.046 & 0.921 & 0.698 & Accepted \\
Material sourcing & -0.035 & 0.910 & 0.690 & Accepted \\
Manufacturing processes & -0.067 & 0.942 & 0.711 & Accepted \\
Digital platform effectiveness & -0.073 & 0.948 & 0.715 & Accepted \\
Digital communication & -0.054 & 0.929 & 0.702 & Accepted \\
\hline Threshold $D$ & & & 0.642 & \\
\hline
\end{tabular}

Table A3. FDM results for criteria.

\begin{tabular}{|c|c|c|c|c|}
\hline Initial Criteria & $o_{b}$ & $s_{b}$ & $L_{b}$ & Decision \\
\hline Investment recovery & 0.000 & 0.500 & 0.33333 & Unaccepted \\
\hline Production stage & -0.417 & 0.917 & 0.61130 & Unaccepted \\
\hline Operations practices & -0.031 & 0.906 & 0.68710 & Accepted \\
\hline Strategic supplier collaboration & -0.056 & 0.931 & 0.70395 & Accepted \\
\hline Product quality & -0.096 & 0.971 & 0.73095 & Accepted \\
\hline Logistics integration & -0.067 & 0.942 & 0.71102 & Accepted \\
\hline Logistics optimization & -0.052 & 0.927 & 0.70103 & Accepted \\
\hline Sourcing flexibility & -0.048 & 0.923 & 0.69859 & Accepted \\
\hline Social rollaboration & -0.351 & 0.851 & 0.56714 & Unaccepted \\
\hline Corporate practice transparency & 0.000 & 0.500 & 0.33333 & Unaccepted \\
\hline Social responsibility & -0.342 & 0.842 & 0.56152 & Unaccepted \\
\hline Top management commitment & 0.295 & 0.955 & 0.80314 & Accepted \\
\hline Working conditions & -0.055 & 0.930 & 0.70350 & Accepted \\
\hline Worker safety & 0.287 & 0.963 & 0.80842 & Accepted \\
\hline Labor rights & -0.001 & 0.876 & 0.66718 & Accepted \\
\hline Child labor or forced labor & 0.000 & 0.500 & 0.33333 & Unaccepted \\
\hline Green purchasing & -0.351 & 0.851 & 0.56714 & Unaccepted \\
\hline Eco collaboration & -0.343 & 0.843 & 0.56233 & Unaccepted \\
\hline Supplier green management & 0.000 & 0.500 & 0.33333 & Unaccepted \\
\hline Recycling (or reverse logistics) & -0.336 & 0.836 & 0.55761 & Unaccepted \\
\hline Cleaner production & -0.018 & 0.893 & 0.67875 & Accepted \\
\hline Waste minimisation and recovery & -0.405 & 0.905 & 0.60324 & Unaccepted \\
\hline Green packaging & -0.369 & 0.869 & 0.57918 & Unaccepted \\
\hline Eco product design & -0.375 & 0.875 & 0.58346 & Unaccepted \\
\hline Delivery speed & -0.070 & 0.945 & 0.71357 & Accepted \\
\hline Adaption flexibility & -0.059 & 0.934 & 0.70598 & Accepted \\
\hline Autonomous decision-making & -0.390 & 0.890 & 0.59316 & Unaccepted \\
\hline Process scalability & -0.033 & 0.908 & 0.68849 & Accepted \\
\hline Innovative approaches & -0.069 & 0.944 & 0.71252 & Accepted \\
\hline Proactive action & -0.018 & 0.893 & 0.67834 & Accepted \\
\hline Eco-friendly & -0.373 & 0.873 & 0.58170 & Unaccepted \\
\hline Global connectivity & -0.028 & 0.903 & 0.68520 & Accepted \\
\hline Real-time inventory & -0.073 & 0.948 & 0.71509 & Accepted \\
\hline Information transparency & 0.303 & 0.947 & 0.79796 & Accepted \\
\hline Relationship performance & -0.073 & 0.948 & 0.71509 & Accepted \\
\hline Threshold $D$ & & & 0.62877 & \\
\hline
\end{tabular}

\section{References}

1. Alkhuzaim, L.; Zhu, Q.; Sarkis, J. Evaluating Emergy Analysis at the Nexus of Circular Economy and Sustainable Supply Chain Management. Sustain. Prod. Consum. 2021, 25, 413-424. [CrossRef]

2. Buyukozkan, G.; Gocer, F. Digital Supply Chain: Literature review and a proposed framework for future research. Comput. Ind. 2018, 97, 157-177. [CrossRef] 
3. Das, D. The impact of Sustainable Supply Chain Management practices on firm performance: Lessons from Indian organizations. J. Clean. Prod. 2018, 203, 179-196. [CrossRef]

4. Hong, J.; Zhang, Y.; Dign, M. Sustainable supply chain management practices, supply chain dynamic capabilities, and enterprise performance. J. Clean. Prod. 2018, 172, 3508-3519. [CrossRef]

5. Indonesian Footwear Industry Country Report 2019; Indonesia Footwear Association: Jakarta, Indonesia, 2019.

6. Khan, S.A.R.; Yu, Z.; Golpira, H.; Sharif, A.; Mardani, A. A state-of-the-art review and meta-analysis on sustainable supply chain management: Future research directions. J. Clean. Prod. 2021, 278, 123357. [CrossRef]

7. The Ministry of Industry of Indonesia. Produksi Industri Alas Kaki RI Pijak Posisi 4 Dunia. 2019. Available online: https: / / kemenperin.go.id/artikel/20538/Produksi-Industri-Alas-Kaki-RI-Pijak-Posisi-4-Dunia (accessed on 25 June 2021).

8. Tsai, F.M.; Bui, T.-D.; Tseng, M.-L.; Ali, M.H.; Lim, M.K.; Chiu, A.S.F. Sustainable supply chain management trends in world regions: A data-driven analysis. Resour. Conserv. Recycl. 2021, 167, 105421. [CrossRef]

9. World Footwear. Indonesian Footwear Exports with 8.97\% Annual Growth. 2021. Available online: https:/ /www.worldfootwear. com/news/indonesian-footwear-exports-with-897-annual-growth/6093.html (accessed on 25 June 2021).

10. Munny, A.A.; Ali, S.M.; Kabir, G.; Moltadir, M.A.; Rahman, T.; Mahtab, Z. Enablers of social sustainability in the supply chain: An example of footwear industry from an emerging economy. Sustain. Prod. Consum. 2019, 20, 230-242. [CrossRef]

11. Tseng, M.-L.; Wu, K.-J.; Lim, M.K.; Wong, W.-P. Data-driven sustainable supply chain management performance: A hierarchical structure assessment under uncertainties. J. Clean. Prod. 2019, 227, 760-771. [CrossRef]

12. Ahemd, W.; Sarkar, B. Management of next-generation energy using a triple bottom line approach under a supply chain framework. Resour. Conserv. Recycl. 2019, 150, 104431. [CrossRef]

13. Annosi, M.C.; Brunetta, F.; Bimbo, F.; Kostoula, M. Digitalization within food supply chains to prevent food waste. Drivers, barriers and collaboration practices. Ind. Mark. Manag. 2021, 93, 208-220. [CrossRef]

14. Beaulieu, M.; Bentahar, O. Digitalization of the healthcare supply chain: A roadmap to generate benefits and effectively support healthcare delivery. Technol. Forecast. Soc. Chang. 2021, 167, 120717. [CrossRef]

15. Barrett, J.; Scott, K. Link between climate change mitigation and resource efficiency: A UK case study. Glob. Environ. Chang. 2012, 22, 299-307. [CrossRef]

16. Bruque Camara, S.; Moyano Fuentes, J.; Maqueira Martin, J.M. Cloud computing, Web 2.0, and operational performance. Int. J. Logist. Manag. 2015, 26, 426-458. [CrossRef]

17. Tseng, M.L.; Tran, T.P.; Ha, H.M.; Bui, T.D.; Lim, M.K. Sustainable industrial and operation engineering trends and challenges Toward Industry 4.0: A data driven analysis. J. Ind. Prod. Eng. 2021, 1-8. [CrossRef]

18. Chen, C.-C.; Sujanto, R.Y.; Tseng, M.-L.; Fujii, M.; Lim, M.K. Sustainable consumption transition model: Social concerns and waste minimization under willingness-to-pay in Indonesian food industry. Resour. Conserv. Recycl. 2021, 170, 105590. [CrossRef]

19. Tseng, M.-L.; Bui, T.-D. Identifying eco-innovation in industrial symbiosis under linguistic preferences: A novel hierarchical approach. J. Clean. Prod. 2017, 140, 1376-1389. [CrossRef]

20. Tseng, M.-L.; Lim, M.K.; Wong, W.-P.; Chen, Y.-C.; Zhan, Y. A framework for evaluating the performance of sustainable service supply chain management under uncertainty. Int. J. Prod. Econ. 2018, 195, 359-372. [CrossRef]

21. Hu, J.; Liu, Y.-L.; Yuen, T.W.W.; Lim, M.K.; Hu, J. Do green practices really attract customers? The sharing economy from the sustainable supply chain management perspective. Resour. Conserv. Recycl. 2019, 149, 177-187. [CrossRef]

22. Genovese, A.; Acquaye, A.A.; Figueroa, A.; Koh, S.L. Sustainable supply chain management and the transition towards a circular economy: Evidence and some applications. Omega 2017, 66, 344-357. [CrossRef]

23. Bhargava, B.; Ranchai, R.; Othmane, L.B. Secure information sharing in digital supply chains. In Proceedings of the $20133 \mathrm{rd}$ IEEE International Advance Computing Conference (IACC), Ghaziabad, India, 22-23 February 2013; pp. 1636-1640.

24. Queiroz, M.M.; Pereira, S.C.F.; Telles, R.; Machado, M.C. Industry 4.0 and digital supply chain capabilities. Benchmarking Int. J. 2019. [CrossRef]

25. Nasira, M.; Ukko, J.; Saunila, M.; Rantala, T. Managing the digital supply chain: The role of smart technologies. Technovation 2020, 96-97, 102121. [CrossRef]

26. Balta, M.; Valsecchi, R.; Papadopoulos, T.; Bourn, D.J. Digitalization and co-creation of healthcare value: A case study in Occupational Health. Technol. Forecast. Soc. Chang. 2021, 168, 120785. [CrossRef]

27. Fettermann, D.C.; Cavalcante, C.G.; Almeida, T.D.; Tortorella, G.L. How does Industry 4.0 contribute to operations management? J. Ind. Prod. Eng. 2018, 35, 255-268. [CrossRef]

28. Kianpour, P.; Gupta, D.; Krishnan, K.K.; Gopalakrishnan, B. Automated job shop scheduling with dynamic processing times and due dates using project management and industry 4.0. J. Ind. Prod. Eng. 2021, 1-4. [CrossRef]

29. Filho, J.C.; Nunhes, T.V.; Oliveira, O.J. Guidelines for cleaner production implementation and management in the plastic footwear industry. J. Clean. Prod. 2019, 232, 822-838. [CrossRef]

30. Moktadir, M.A.; Dwivedi, A.; Khan, N.S.; Paul, S.K.; Khan, S.A.; Ahmed, S.; Sultana, R. Analysis of risk factors in sustainable supply chain management in an emerging economy of leather industry. J. Clean. Prod. 2021, 283, 124641. [CrossRef]

31. Bui, T.D.; Tsai, F.M.; Tseng, M.-L.; Ali, M.H. Identifying sustainable solid waste management barriers in practice using the fuzzy Delphi method. Resour. Conserv. Recycl. 2020, 154, 104625. [CrossRef]

32. Tseng, M.-L.; Wu, K.-J.; Lee, C.-H.; Lim, M.K.; Bui, T.-D.; Cchen, C.-C. Assessing sustainable tourism in Vietnam: A hierarchical structure approach. J. Clean. Prod. 2018, 195, 406-417. [CrossRef] 
33. Tseng, M.-L.; Wu, K.-J.; Chiu, A.S.F.; Lim, M.K.; Tan, K. Service innovation in sustainable product service systems: Improving performance under linguistic preferences. Int. J. Prod. Econ. 2019, 217, 159-170. [CrossRef]

34. Tsai, F.-M.; Bui, T.D.; Tseng, M.-L.; Lim, M.K.; Wu, K.-J.; Mashud, A.H.M. Assessing a hierarchical sustainable solid waste management structure with qualitative information: Policy and regulations drive social impacts and stakeholder participation. Resour. Conserv. Recycl. 2021, 168, 105285. [CrossRef]

35. Roy, V.; Schoenherr, T.; Charan, P. Toward an organizational understanding of the transformation needed for sustainable supply chain management: The concepts of force-field and differential efforts. J. Purch. Supply Manag. 2020, 26, 100612. [CrossRef]

36. Lim, M.K.; Tseng, M.-L.; Tan, K.H.; Bui, T.D. Knowledge management in sustainable supply chain management: Improving performance through an interpretive structural modelling approach. J. Clean. Prod. 2017, 162, 806-816. [CrossRef]

37. Bubics, M.E.; Dias Barbosa-Povoa, A.P.F.; Carvalho, A. Social sustainability management in the apparel supply chains. J. Clean. Prod. 2021, 280, 124214. [CrossRef]

38. Mathivathanan, D.; Kannan, D.; Haq, A.N. Sustainable supply chain management practices in Indian automotive industry: A multi-stakeholder view. Resour. Conserv. Recycl. 2018, 128, 284-305. [CrossRef]

39. Roy, S.; Das, M.; Ali, S.M.; Raihan, A.S.; Paul, S.K.; Kabir, G. Evaluating strategies for environmental sustainability in a supply chain of an emerging economy. J. Clean. Prod. 2020, 262, 121389. [CrossRef]

40. Tseng, M.-L.; Chiu, A.S.F. Evaluating firm's green supply chain management in linguistic preferences. J. Clean. Prod. 2013, 40, 22-31. [CrossRef]

41. Zhang, T.; Xin, Y. A truthful online auction mechanism for deadline-aware cloud resource allocation. In Proceedings of the 2018 IEEE/IFIP Network Operations and Management Symposium (NOMS 2018), Taipei, Taiwan, 23-27 April 2018; pp. 1-9.

42. Ishikawa, A.; Amagasa, M.; Shiga, T.; Tomizawa, G.; Tatsuta, R.; Mieno, H. The max-min Delphi method and fuzzy Delphi method via fuzzy integration. Fuzzy Sets Syst. 1993, 55, 241-253. [CrossRef] 